\title{
Type C Behavior and Associated Factors in Patients with Breast Cancer During Postoperative Chemotherapy: A Cross-Sectional Study
}

\author{
Xiao-Ying Shen ${ }^{1, *}$ \\ Yu-Ping Lin $\mathbb{D}^{2, *}$ \\ Run-Na Miao $\mathbb{D D}^{3}$ \\ Xue $\mathrm{Yao}^{4}$ \\ Hui Sun ${ }^{5}$ \\ Wei Yang ${ }^{5}$
}

'Second Clinical Medical College, Harbin Medical University, Harbin, People's Republic of China; ${ }^{2}$ School of Nursing, Fudan University, Shanghai, People's Republic of China; ${ }^{3}$ Department of Nursing, Health Science Centre, Xi'an Jiaotong University, Xi'an, People's Republic of China; ${ }^{4}$ School of Nursing, Shandong University, Shandong, People's Republic of China; ${ }^{5}$ Heilongjiang Second Hospital, Harbin, People's Republic of China

*These authors contributed equally to this work
Correspondence: Xiao-Ying Shen

Second Clinical Medical College, Harbin

Medical University, Harbin, I50086,

People's Republic of China

Tel +8613351883728

Email 337372672@qq.com
Background: Type $\mathrm{C}$ behavior is a cancer-prone behavior that can affect the occurrence and development of cancer. This study aimed to investigate the prevalence of type $\mathrm{C}$ behavior in patients with breast cancer during postoperative chemotherapy and determine its associated factors. Methods: This study enrolled 161 patients with breast cancer who received postoperative chemotherapy. Type $\mathrm{C}$ personality behavior pattern questionnaire was used to assess type $\mathrm{C}$ behavior patterns. The following instruments were employed: medical coping modes questionnaire, social support scale, social relational quality scale, Herth hope index. logistic regression was used to identify the factors affecting type $\mathrm{C}$ behavior.

Results: The incidence of type $\mathrm{C}$ behavior was 28\%. Participants aged 45-59 years $(\mathrm{OR}=3.62,95 \% \mathrm{CI}=1.04-12.56, \mathrm{P}=0.043)$, and who adopted a resignation coping style $(\mathrm{OR}=1.25,95 \% \mathrm{CI}=1.03-1.50, \mathrm{P}=0.021)$, were more likely to develop type $\mathrm{C}$ behavior. Type $\mathrm{C}$ behavior was less common in patients with employment $(\mathrm{OR}=0.38$, $95 \% \mathrm{CI}=0.15-0.97, \mathrm{P}=0.043)$, with a high level of social support $(\mathrm{OR}=0.89,95 \% \mathrm{CI}=$ $0.80-0.98, \mathrm{P}=0.023)$, and more hope $(\mathrm{OR}=0.83,95 \% \mathrm{CI}=0.71-0.98, \mathrm{P}=0.079)$.

Conclusion: In this study, $28 \%$ patients with breast cancer during postoperative chemotherapy exhibited type $\mathrm{C}$ behavior. Associated factors with type $\mathrm{C}$ behavior were identified, which could guide health care professionals to reduce the prevalence of type $\mathrm{C}$ behavior through guiding patients to adopt positive coping styles and improving their level of social support and hope, especially in those aged 45 to 59 years or in those without employment. Keywords: breast cancer, type $\mathrm{C}$ behavior, coping style, social support, social relational quality, hope

\section{Introduction}

Breast cancer is the most common cancer in women, with the highest incidence among malignancies in female patients. ${ }^{1}$ According to the latest estimations of the International Agency for Research on Cancer (IARC) of the World Health Organization, 2020 saw 2.3 million new cases of breast cancer, accounting for $11.7 \%$ of the total number of new cancers cases, which will replace lung cancer as the most common cancer in the world. ${ }^{2}$ In China, there were an estimated 420,000 new cases of breast cancer in 2020. Data from the China Cancer Registration Center show that from 1973 to 2015, the incidence and mortality of breast cancer in Chinese women increased gradually. ${ }^{3,4}$

Type $\mathrm{C}$ behavior is a cancer-prone behavior that is characterized by being passive, depression, suppression of anger, and emotional instability. ${ }^{5}$ One recent 
study proposed a two-facet structure of type $\mathrm{C}$ behavior, which includes Submissiveness (the interpersonal aspect) and Restricted Affectivity (the intrapersonal aspect), reconceptualizing type $\mathrm{C}$ behavior based on theoretical analysis and classical literature. ${ }^{6}$ Type $\mathrm{C}$ behavior is often considered to be one of the risk factors for cancer, in that it can weaken the immune system through neuroendocrine and other mechanisms to generate tumors and further reduce the therapeutic effect in patients with cancer. $^{7}$

It has been reported that $40-80 \%$ of patients with cancer experience depressive emotions and a low mood. ${ }^{8}$ In a Columbian case-control study that explored the risk factors of breast cancer, $95.1 \%$ of patients in the case group exhibited type $\mathrm{C}$ behavior characteristics. ${ }^{9}$ In another Chinese study, the incidence was $31.3 \% .{ }^{10}$ However, the scales used were not the same between these two studies. Furthermore, most previous studies have used the type $\mathrm{C}$ behavior characteristic scale to verify that patients with breast cancer had type $\mathrm{C}$ behavior, which can not directly reflect its concrete proportion among those people. ${ }^{11}$ Therefore, the overall situation of type $\mathrm{C}$ behavior in patients with breast cancer is not clear, and more research is required.

Among the therapeutic plans, chemotherapy plays an irreplaceable role in breast cancer. ${ }^{12}$ During postoperative chemotherapy, patients with breast cancer often experience body changes caused by surgery and physical discomfort caused by the side effects of chemotherapy. ${ }^{13,14}$ Hence, under the double blow of adverse reactions from surgery and chemotherapy, patients in this stage of treatment are prone to negative emotions such as anxiety and depression, which can further affect their quality of life. Many studies have shown that patients with type $\mathrm{C}$ behavior are more likely to suffer from negative emotions. These results suggesting that patients with type $\mathrm{C}$ behavior are more likely to suffer from negative emotions. ${ }^{15,16}$ On the contrary, patients with breast cancer with positive personality traits are more able to express their inner unpleasant experiences and report fewer chemotherapy-related symptoms; thus, they can better adapt to the adverse physical and mental effects caused by postoperative chemotherapy. ${ }^{17}$

At present, most type $\mathrm{C}$ behavior-related studies in patients with breast cancer have focused on the description of the behavioral characteristics, or the analysis of the correlation at home and abroad. Du found that there was a significant correlation between anxiety, depression and type $\mathrm{C}$ behavior in patients with gynecological malignant tumors during the perioperative period. ${ }^{16}$ This correlation has also been confirmed in other studies. ${ }^{15,23,24}$ Liu et al pointed out that social support is also associated with type $\mathrm{C}$ behavior in patients on maintenance hemodialysis. In addition, one study have reported a correlation between serum cortisol and type $\mathrm{C}$ behavior in patients with cancer. $^{25}$

However, few studies have investigated the occurrence of type $\mathrm{C}$ behavior in patients with breast cancer and its influencing factors. This study applied the Stress Model System, which claims that an individual is a multi-factor system that includes life events, cognitive evaluation, coping style, social support, and personality characteristics. ${ }^{31}$ To conclude, this study investigated type $\mathrm{C}$ behavior in patients with breast cancer and its associated factors.

\section{Methods}

\section{Study Design}

This cross-sectional study was conducted in the Breast Surgery Department of the Second Affiliated Hospital of Harbin Medical University and the Affiliated Tumor Hospital of Harbin Medical University from June 2019 to January 2020 in China. The inclusion criteria were as follows: aged 18 years or more; diagnosed with breast cancer in pathology; undergoing postoperative chemotherapy for breast cancer; no verbal communication limitations or dyslexia; informed consent. People with a history of mental illness, severe physical disorders, or previous malignancy in other locations, or recurrences were excluded.

\section{Sample Size}

The sample size was calculated using a single populationproportion formula $\frac{z^{2} p(1-p)}{d^{2}}$. Considering the estimated odds of type $\mathrm{C}$ behavior in patients with breast cancer during postoperative chemotherapy has been reported to be $31.1 \%$ in a study in China. ${ }^{10}$ We adopted an a $8 \%$ margin of error at $95 \% \mathrm{CI}$.

Considering an estimated $25 \%$ non-response rate, the total study subjects required was calculated to be $129+32$ $=161$ patients with breast cancer.

Nonprobability convenience sampling was used for this study.

\section{Procedures}

After obtaining the ethical approval for the hospital and the department, researchers were uniformly trained to collect questionnaires for patients who met the inclusion 
criteria. Uniform instructions were used to inform patients at the bedside, and informed consent was signed before the data collection. The questionnaire was collected on the spot and carefully checked. If there were any mistakes or omissions in the questionnaire, the patients were instructed to fill in the missing information. Ethical approval was obtained from the Institutional Review Committee of the Second Affiliated Hospital of Harbin Medical University (Reference number: KY2019-0118). The study was conducted in accordance with the Declaration of Helsinki.

\section{Measures}

Self-filled questionnaires were divided into three parts. The first part investigated the general information on the study subjects, including demographic and disease-related information. The second part assessed the incidence of type $\mathrm{C}$ behavior. The third part measured psychosocial factors that can be potentially associated with type $\mathrm{C}$ behavior.

The demographic data collected included age, work status, education level, religious belief, marital status, economic status, menopausal status, and knowledge of breast cancer. Disease-related information collected included the type of surgery and disease duration.

The type $\mathrm{C}$ personality behavior pattern questionnaire was used to assess the presence of type $\mathrm{C}$ behavior. It was designed by Temoshok and introduced into China by Yao Zhang et al. The questionnaire includes 16 items, and a score of 14 or above indicates a typical type $\mathrm{C}$ behavior pattern, including severe depression, anxiety, and paranoid personality. A score of 11-13 indicates a type $\mathrm{C}$ behavior pattern, with a tendency towards depression, guilt, anxiety, and paranoid personality. Patients with 7-10 points have mild type $C$ behavior patterns. A score of 6 or below indicates that patients do not exhibit a type C behavior pattern. ${ }^{18}$

Psychosocial factors that might affect type $\mathrm{C}$ behavior included coping style, social support, quality of social relationships, and hope.

The Medical Coping Mode Questionnaire (MCMQ) was used to assess the coping style of subjects. It was compiled by FeifelH et al, and Sinicized and revised by Xiaohong Shen et al. The MCMQ has 20 items, which measure three dimensions - confrontation, avoidance, and resignation. The MCMQ items are scored on a Likert 4-grade scale, with 8 items scored in reverse. The scale has good reliability and validity, the Cronbach's alpha values of the three dimensions are $0.69,0.60$, and 0.76 , respectively, and the test-retest reliability is $0.64,0.85$, and 0.67 , respectively. ${ }^{19}$
The 10-items Social Support Scale (SSRS) was used to assess the $t$ social support level, which is divided into three dimensions of objective support, subjective support, and availability of support. It was designed by Shuiyuan Xiao, a domestic scholar. The SSRS is the most commonly used scale to evaluate social support in China. The total score of the scale is the sum of all items, with a higher score indicating a higher level of social support. A total score below 33, 33-45, and 45 or more indicate a low, moderate, and high degree of social support, respectively. The Cronbach's alpha coefficient is 0.92 , and the consistency of each item is $0.89-0.94 .^{20}$

To measure quality of social relationships, we used the 17-item Social Relational Quality Scale (SRQS). The SRQS was originally developed by five experts from the University of Hong Kong and Queen Elizabeth Medical School for the study of patients with colorectal cancer. The SRQS measures three dimensions - family intimacy, family commitment, and friendship. Each item is scored on a Likert scale ranging from 1 to 4 , with a total possible score of 17-68. A higher score indicates a better relationship between patients and their families and friends. The Cronbach's alpha values of the three dimensions are 0.80 , 0.82 , and 0.75 , respectively. ${ }^{21}$

Herth Hope Index Scale (HHI) was compiled by the American scholar Herth, and introduced into China by Haiping Zhao of China Medical University. The HHI was used to measure the level of hope. The 12-item scale includes three dimensions-temporality and future, positive readiness and expectancy, and interconnectedness. Items are scored on a 4-point Likert-type scale, and a higher score indicates a higher level of hope. The total possible score ranges from 12-48. There are three grades, as follows: low (12-23), medium (24-35), and high (36-48). The Cronbach's alpha coefficient is $0.92 .^{22}$

\section{Data Analysis}

The valid questionnaires were numbered. The data were input with EpiDate 3.1 and analyzed using SPSS 17.0. A univariate analysis was used to using examine the potential associated factors using $\chi 2$ test, $t$ test or Mann-Whitney $U$-test. Logistic regression was applied to further obtain the associated factors after controlling for confounding variables. Variables with an association at $\mathrm{P}<0.20$ in the univariate analysis were entered into the multivariate analysis, and those variables with $\mathrm{P}<0.05$ in the multivariate analysis were considered to be statistically significant. 


\section{Results}

A total of 45 patients were found to exhibit a type $\mathrm{C}$ behavior pattern in this study with an overall incidence of $28 \%$ (Table 1 ).

Patients were subdivided into a type $\mathrm{C}$ behavior group and a non-type $\mathrm{C}$ behavior group according to the cutoff score of 6 . Tables 2 and 3 present the distribution of demographic characteristics, disease characteristics, and psychosocial factors between the two groups. The results showed that age $(P=0.029)$, work status $(P=0.002)$, and education level $(\mathrm{P}=0.015)$ were correlated with the occurrence of type $\mathrm{C}$ behavior among participants. Furthermore, patients aged 45-59 years, who were unemployed, and/or had a high school education level or less had a higher proportion of type $\mathrm{C}$ behavior. Additionally, among the psychosocial factors, resignation $(\mathrm{P}<0.001)$, level of social support $(\mathrm{P}<$ $0.001)$, quality of social relationships $(\mathrm{P}<0.001)$, and hope $(\mathrm{P}<0.001)$ were also shown to be associated with the occurrence of type $\mathrm{C}$ behavior.

By constructing a logistic regression model using the univariate analysis results and combining with clinical knowledge, variables that could affect the occurrence of type $\mathrm{C}$ behavior were included in the multivariate analysis model. The results showed that age, work status, resignation, social support level, and hope were independently correlated with the occurrence of type $\mathrm{C}$ behavior (Table 4).

Women aged 45 to 59 years were 3.62 times more likely to exhibit type $\mathrm{C}$ behavior than their counterparts. Women who were employed were 0.38 times more likely to exhibit type $\mathrm{C}$ behavior than those who were unemployed. Women who had a tendency to adopt a resignation coping style were 1.25 times more likely to exhibit type $\mathrm{C}$ behavior than women who chose other coping styles. Women with a higher social support level were 0.89 times more likely to exhibit type $\mathrm{C}$ behavior than women who did not have adequate social support. Women with higher levels of hope were 0.83 times more likely to exhibit type $\mathrm{C}$ behavior than their counterparts (Table 4).

Table I The Occurrence of Type C Behavior

\begin{tabular}{|l|c|c|}
\hline Score Ranges & N & $\%$ \\
\hline$\leqq 6$ & 116 & 72.0 \\
$7 \sim 10$ & 40 & 24.8 \\
$11 \sim 13$ & 4 & 2.5 \\
$\geqq 14$ & $\mathrm{I}$ & 0.7 \\
\hline
\end{tabular}

\section{Discussion}

This study recruited patients with breast cancer who underwent surgery with chemotherapy. All patients therefore faced the same stress of breast cancer, and had been suffering from the rapid adverse physical and psychological effects of surgery and chemotherapy. According to this, the incidence of type $\mathrm{C}$ behavior in this phase could be expected to be at a higher level. As Bonilla et al have shown, the incidence rate of type $\mathrm{C}$ behavior can be as high as $95.1 \% .{ }^{9}$ However, only $31.3 \%$ was reported by another study, ${ }^{10}$ which was more similar to the $28 \%$ incidence rate found in our study. Compared with the results of Bonilla et al, our result was at a moderately low level. On the one hand, according to our findings, this may be due to the different age distribution and work status of the study groups selected in each study. Alternatively, it could be linked to the repressive characteristics of the type $\mathrm{C}$ behavior itself. ${ }^{17}$

Most studies focused on the analysis of correlation or mediating relationships between variables, and type $\mathrm{C}$ behavior has usually been considered as a prevariable to illustrate the practical significance. However, this study took a different perspective and set type $\mathrm{C}$ behavior as the outcome variable to focus on its influencing factors, which is also a highlight in this study. According to the regression model results, age, work status, resignation, social support level, and hope were determined as the independent factors associated with type $\mathrm{C}$ behavior.

In terms of demographic characteristics, we found that people aged 45-59 years or who were unemployed were more likely to exhibit type $\mathrm{C}$ behavior. This might because patients of this age may have more family and work responsibilities, and may be under more stress than other age groups in China. Furthermore, the occurrence of breast cancer can mean that patients detach from their original roles and have a greater psychological burden, which can easily induce negative emotions. Additionally, unemployed patients are more likely face economic problems because of large medical expenses.

This study identified three significant psychosocial factors associated with type $\mathrm{C}$ behavior. First, type $\mathrm{C}$ behavior was more likely to occur in patients who adopted a resignation coping style. Resignation is a negative coping mode during which patients rarely seek external support, and instead suppress the negative emotions on their own, which cannot be quickly remedied, and thus prone to type $\mathrm{C}$ behavior. Second, the higher the level of social support, the lower the incidence of type $\mathrm{C}$ behavior. On the one hand, a good social support 
Table 2 Descriptive Statistics of Demographic and Disease-Related Variables in Groups with Type C Behavior and Non-Type-C Behavior

\begin{tabular}{|c|c|c|c|c|}
\hline \multicolumn{2}{|l|}{ Variables } & \multirow{2}{*}{$\begin{array}{c}\text { Type C Behavior }(\mathbf{N}=\mathbf{4 5}) \\
5(11.1) \\
34(75.6) \\
6(13.3)\end{array}$} & \multirow{2}{*}{$\begin{array}{c}\text { Non- Type-C Behavior (N= I I 6) } \\
32(27.6) \\
62(53.4) \\
22(19)\end{array}$} & \multirow{2}{*}{$\frac{P}{0.029^{a}}$} \\
\hline Age & $\begin{array}{l}<45 \\
45-59 \\
\geq 60\end{array}$ & & & \\
\hline Work status & $\begin{array}{l}\text { Unemployed } \\
\text { Employed }\end{array}$ & $\begin{array}{l}28(62.2) \\
17(37.8)\end{array}$ & $\begin{array}{l}4 I(35.3) \\
75(64.7)\end{array}$ & $0.002^{\mathrm{a}}$ \\
\hline Educational level & $\begin{array}{l}\text { High school or below } \\
\text { Undergraduate and above }\end{array}$ & $\begin{array}{c}42(93.2) \\
3(6.8)\end{array}$ & $\begin{array}{l}89(76.7) \\
27(23.3)\end{array}$ & $0.015^{a}$ \\
\hline Religious beliefs & $\begin{array}{l}\text { Yes } \\
\text { No }\end{array}$ & $\begin{array}{c}39(86.7) \\
16(3.3)\end{array}$ & $\begin{array}{l}90(77.6) \\
26(22.4)\end{array}$ & $0.195^{\mathrm{a}}$ \\
\hline Marital status & $\begin{array}{l}\text { Married } \\
\text { Other (single, divorced, widowed) }\end{array}$ & $\begin{array}{l}35(77.8) \\
10(22.2)\end{array}$ & $\begin{array}{l}101(87.1) \\
15(12.9)\end{array}$ & $0.14^{\mathrm{a}}$ \\
\hline Economic status & $\begin{array}{l}<1000 \text { yuan } \\
1000-3000 \text { yuan } \\
3001-5000 \text { yuan } \\
>5000 \text { yuan }\end{array}$ & $\begin{array}{c}\mid 4(3|.|) \\
2 \mid(46.7) \\
9(20) \\
I(2.2)\end{array}$ & $\begin{array}{l}26(22.4) \\
49(42.2) \\
25(21.6) \\
16(13.8)\end{array}$ & $0.15^{\mathrm{a}}$ \\
\hline Menopausal status & $\begin{array}{l}\text { Yes } \\
\text { No }\end{array}$ & $\begin{array}{l}25(55.6) \\
20(44.4)\end{array}$ & $\begin{array}{l}58(50) \\
58(50)\end{array}$ & $0.53^{\mathrm{a}}$ \\
\hline Knowledge of disease & $\begin{array}{l}\text { Not clear } \\
\text { Little } \\
\text { Much } \\
\text { Complete }\end{array}$ & $\begin{array}{c}7(15.6) \\
34(75.6) \\
3(6.7) \\
I(2.2)\end{array}$ & $\begin{array}{l}21(18.1) \\
70(60.3) \\
22(19) \\
3(2.6)\end{array}$ & $0.19^{\mathrm{a}}$ \\
\hline Type of surgery & $\begin{array}{l}\text { Modified radical mastectomy } \\
\text { Simple mastectomy } \\
\text { Breast conserving surgery }\end{array}$ & $\begin{array}{l}24(53.3) \\
15(33.3) \\
6(13.3)\end{array}$ & $\begin{array}{c}65(56) \\
38(32.8) \\
13(11.2)\end{array}$ & $0.92^{\mathrm{a}}$ \\
\hline Disease duration & $\begin{array}{l}\leq \text { I year } \\
>\text { I year }\end{array}$ & $\begin{array}{l}25(55.6) \\
20(44.4)\end{array}$ & $\begin{array}{l}64(55.2) \\
52(44.8)\end{array}$ & $0.97^{\mathrm{a}}$ \\
\hline
\end{tabular}

Notes: Significant differences between groups $(\mathrm{P}<0.05)$ in bold. ${ }^{\text {a Pearson }}$ chi-squared.

system can reduce the generation of destructive emotions and contribute to the ability to express inner feelings to family and friends, and thus to avoid the occurrence of type $\mathrm{C}$ behavior. ${ }^{26}$ During the process of investigation, we also found that widowed or divorced patients were most commonly in poor condition due to the lack of good social support, as one patient reported that, "at the sight of other patients being surrounded by people, I can't help but run to the hall and cry". Finally, we also found that patients with high levels of hope were less likely to incorporate type $\mathrm{C}$ behavior. Hope can help patients face their disease more actively. ${ }^{27}$ Patients with a high level of hope might also better regulate the adverse emotions caused by the disease. ${ }^{28,29}$
The results of this study provide novel insights for the development of psychological interventions for patients with breast cancer, and type $\mathrm{C}$ behavior can be modified through human intervention. For instance, one study reported that the combination of spouse concurrent cognitive therapy and psychological intervention that increases social support sources from their family can change the negative behavior of patients, which is consistent with our results. ${ }^{30}$ Therefore, we suggest that health professionals treating patients with breast cancer during chemotherapy after surgery should identify and correct negative coping styles in a timely manner. Health care professionals should also simultaneously assess the patient's level of hope to 
Table 3 Descriptive Statistics of Psychosocial Variables in Groups with Type C Behavior and Non-Type-C Behavior

\begin{tabular}{|c|c|c|c|}
\hline Variables & Type C Behavior ( $N=45)$ & Non- Type-C Behavior $(\mathrm{N}=\mid 16)$ & $\mathbf{P}$ \\
\hline \multicolumn{4}{|c|}{ Medical coping mode } \\
\hline \multicolumn{4}{|l|}{ Confrontation } \\
\hline$M( \pm 95 \% \mathrm{Cl})$ & $19.6(\mid 8.3-21.0)$ & 19.5(18.7-20.3) & $0.85 \mathrm{I}^{\mathrm{b}}$ \\
\hline SD & 4.5 & 4.3 & \\
\hline \multicolumn{4}{|l|}{ Avoidance } \\
\hline$M( \pm 95 \% \mathrm{Cl})$ & $16.1(15.1-17.1)$ & $15.5(14.8-16.2)$ & $0.356^{\mathrm{b}}$ \\
\hline SD & 3.4 & 3.8 & \\
\hline \multicolumn{4}{|l|}{ Resignation } \\
\hline$M( \pm 95 \% \mathrm{Cl})$ & $9.8(8.7-10.9)$ & 7.3(6.9-7.7) & $<0.001^{\mathrm{c}}$ \\
\hline $\mathrm{SD}$ & 3.7 & 2.3 & \\
\hline \multicolumn{4}{|l|}{ Social support } \\
\hline$M( \pm 95 \% \mathrm{Cl})$ & $41.0(38.8-43.2)$ & $46.5(45.4-47.7)$ & $<0.001^{c}$ \\
\hline SD & 7.4 & 6.1 & \\
\hline \multicolumn{4}{|c|}{ Obejective support } \\
\hline$M( \pm 95 \% \mathrm{Cl})$ & $10.2(9.2-11.1)$ & $11.1(10.5-11.7)$ & $0.129^{c}$ \\
\hline SD & 3.1 & 3.0 & \\
\hline \multicolumn{4}{|c|}{ Subjective support } \\
\hline$M( \pm 95 \% \mathrm{Cl})$ & $25.1(23.7-26.5)$ & $28.4(27.8-29.0)$ & $<0.001^{\mathrm{C}}$ \\
\hline SD & 4.7 & 3.5 & \\
\hline \multicolumn{4}{|c|}{ Availability of support } \\
\hline$M( \pm 95 \% \mathrm{Cl})$ & $5.8(5.2-6.3)$ & $7.1(6.7-7.4)$ & $<0.001^{\mathrm{C}}$ \\
\hline SD & 1.8 & 2.0 & \\
\hline \multicolumn{4}{|c|}{ Social relational quality } \\
\hline$M( \pm 95 \% \mathrm{Cl})$ & $52.0(50.3-53.7)$ & $55.4(54.3-56.4)$ & $0.001^{c}$ \\
\hline SD & 5.7 & 5.8 & \\
\hline \multicolumn{4}{|c|}{ Family Commitment } \\
\hline$M( \pm 95 \% \mathrm{Cl})$ & $16.4(\mid 5.7-17.0)$ & $17.1(16.7-17.5)$ & $0.068^{c}$ \\
\hline SD & 2.1 & 2.2 & \\
\hline \multicolumn{4}{|l|}{ Family Intimacy } \\
\hline$M( \pm 95 \% \mathrm{Cl})$ & $21.6(20.7-22.5)$ & $22.8(22.3-23.3)$ & $0.04 I^{c}$ \\
\hline SD & 3.0 & 2.8 & \\
\hline \multicolumn{4}{|l|}{ Friendships } \\
\hline$M( \pm 95 \% \mathrm{Cl})$ & $14.0(13.4-14.7)$ & $15.5(15.1-15.9)$ & $<0.001^{\mathrm{C}}$ \\
\hline SD & 2.2 & 2.0 & \\
\hline \multicolumn{4}{|c|}{ Herth hope index } \\
\hline$M( \pm 95 \% \mathrm{Cl})$ & $34.9(33.6-36.3)$ & $37.9(37.2-38.7)$ & $<0.001^{c}$ \\
\hline SD & 4.5 & 4.0 & \\
\hline \multicolumn{4}{|c|}{ Temporality and future } \\
\hline$M( \pm 95 \% \mathrm{Cl})$ & $11.4(10.9-11.9)$ & $12.6(\mid 2.3-12.9)$ & $<0.001^{c}$ \\
\hline SD & 1.7 & 1.5 & \\
\hline \multicolumn{4}{|c|}{ Postive readiness and expectancy } \\
\hline$M( \pm 95 \% \mathrm{Cl})$ & $11.9(11.4-12.5)$ & $12.5(12.3-12.8)$ & $0.122^{c}$ \\
\hline SD & 1.8 & 1.6 & \\
\hline \multicolumn{4}{|c|}{ Interconnectedness } \\
\hline$M( \pm 95 \% \mathrm{Cl})$ & $11.6(11.1-12.1)$ & $12.8(12.6-13.1)$ & $<0.001^{c}$ \\
\hline SD & 1.6 & 1.4 & \\
\hline
\end{tabular}

Notes: Significant differences between groups $(\mathrm{P}<0.05)$ in bold. ${ }^{\mathrm{b}} \mathrm{T}$ test. ${ }^{\mathrm{C}}$ Mann-Whitney $\mathrm{U}$. 
Table 4 Logistic Regression of Occurring Type C Behavior Among Patients with Breast Cancer Undergoing Chemotherapy After Surgery

\begin{tabular}{|c|c|c|c|}
\hline Variables & & OR(95\% CI) & $\mathbf{P}$ \\
\hline Age & $\begin{array}{l}<45 \\
45-59 \\
\geq 60\end{array}$ & $\begin{array}{c}- \\
3.62(1.04-12.56) \\
1.06(0.22-5.16)\end{array}$ & $\begin{array}{c}- \\
0.043 \\
0.94\end{array}$ \\
\hline Work status & $\begin{array}{l}\text { Unemployed } \\
\text { Employed }\end{array}$ & $\begin{array}{c}- \\
0.38(0.15-0.97)\end{array}$ & $\begin{array}{c}- \\
0.043\end{array}$ \\
\hline Educational level & $\begin{array}{l}\text { High school or below } \\
\text { Undergraduate and above }\end{array}$ & $\begin{array}{c}- \\
0.66(0.15-3.04)\end{array}$ & $\begin{array}{c}- \\
0.59\end{array}$ \\
\hline Marital status & $\begin{array}{l}\text { Married } \\
\text { Other(single, divorced, widowed) }\end{array}$ & $\begin{array}{c}- \\
0.46(0.08-2.66)\end{array}$ & $\begin{array}{c}- \\
0.39\end{array}$ \\
\hline Religious beliefs & $\begin{array}{l}\text { Yes } \\
\text { No }\end{array}$ & $\begin{array}{c}- \\
0.36(0.09-1.42)\end{array}$ & $\begin{array}{c}- \\
0.15\end{array}$ \\
\hline Economic status & $\begin{array}{l}<1000 \text { yuan } \\
1000-3000 \text { yuan } \\
3001-5000 \text { yuan } \\
>5000 \text { yuan }\end{array}$ & $\begin{array}{c}- \\
1.39(0.44-4.40) \\
1.62(0.40-6.58) \\
0.11(0.01-1.30)\end{array}$ & $\begin{array}{c}- \\
0.58 \\
0.50 \\
0.080\end{array}$ \\
\hline Knowledge of disease & $\begin{array}{l}\text { Not clear } \\
\text { Little } \\
\text { Much } \\
\text { Complete }\end{array}$ & $\begin{array}{c}- \\
2.85(0.80-10.08) \\
0.85(0.13-5.57) \\
3.19(0.17-60.06)\end{array}$ & $\begin{array}{c}- \\
0.11 \\
0.87 \\
0.44\end{array}$ \\
\hline $\begin{array}{l}\text { Resignation } \\
\text { Social support } \\
\text { Social relational quality } \\
\text { Herth hope level }\end{array}$ & & $\begin{array}{c}1.25(1.03-1.50) \\
0.89(0.80-0.98) \\
1.01(0.91-1.13) \\
0.83(0.71-0.98)\end{array}$ & $\begin{array}{c}0.021 \\
0.023 \\
0.81 \\
0.027\end{array}$ \\
\hline
\end{tabular}

Note: Significant estimates $(P<0.05)$ in bold.

Abbreviations: $\mathrm{OR}$, odds ratio; $\mathrm{Cl}$, confidence interval.

help them better understand the disease and enhance confidence, which could additionally encourage patients to actively seek external sources of support. Medical staff should provide professional information and emotional support to patients, and also guide caregivers to use the correct psychological intervention techniques to ease patients. Particular attention should also be paid to patients with weak social support (such as divorced and widowed patients), and other sources of social support should be fully mobilized, such as cancer parks, cancer clubs, and other peer support. Also, due to the higher probability of type $\mathrm{C}$ behavior in those aged 45-59 years or in unemployed patients, these patients should also receive special support.

\section{Limitations}

This study has some limitations. First, this was a crosssectional study, which can only observe the status quo of various characteristics of study objects within a certain period of time. Future work should aim to conduct longitudinal studies that assess patients for type $\mathrm{C}$ personality at baseline before commencement of treatment, and then follow their progress; this would also provide more robust data with better clinical utility. In addition, we only collected patient data from two hospitals in Harbin, which may not represent the behavioral characteristics of patients in different regions. Therefore, the generalization of the research results to a wider population is limited.

\section{Conclusion}

A total of $28.0 \%$ of patients with breast cancer during postoperative chemotherapy exhibited type $\mathrm{C}$ behavior in our study. Age, work status, resignation, social support, and hope were determined as the independent factors. This implies that health care workers should focus on the patient's psychological needs, identify bad behavior 
characteristics, especially in those aged $45-59$ or who are unemployed. In practice, to prevent the occurrence of type $\mathrm{C}$ behavior, health education programs should be regularly carried out for patients and their caregivers, which would include knowledge of disease, psychological adjustment and others, so as to guide patients to face their diseases exactly, to adopt active coping modes and seek outside support to express inner feelings. Simultaneously, teaching proper psychological counseling methods to patients' caregivers may further assure the effectiveness of any social support received.

\section{Abbreviations}

OR, odds ratio; CI, confidence interval.

\section{Acknowledgment}

The authors would like to thank all study participants and those who have contributed to this study.

\section{Funding}

This study was supported by funding from College Students Innovation and Entrepreneurship Training Program of Harbin Medical University [grant numbers: 201810226123].

\section{Disclosure}

The authors report no conflicts of interest.

\section{References}

1. Cao MM, Chen WQ. Epidemiology of cancer in China and the current status of prevention and control. Chinese $J$ Clin Onco. 2019;46:145-149.

2. Sung H, Ferlay J, Siegel RL, et al. Global cancer statistics 2020: GLOBOCAN estimates of incidence and mortality worldwide for 36 cancers in 185 countries. CA Cancer J Clin. 2021;71(3):209-249. doi:10.3322/caac. 21660 .

3. Shi J, Liang D, Li DJ. Epidemiological status of global female breast cancer. China Cancer. 2017;26:683-690.

4. Wei W, Zeng H, Zheng R, et al. Cancer registration in China and its role in cancer prevention and control. Lancet Oncol. 2020;21 (7):342-349. doi:10.1016/S1470-2045(20)30073-5

5. Baltrusch HJF, Santagostino P. The Type C behavior pattern: newconcepts. Int $J$ Psychophysiol. 1989;7(2-4):126-128. doi:10.1016/0167-8760(89)90075-5

6. Rymarczyk K, Turbacz A, Strus W, et al. Type C personality: conceptual refinement and preliminary operationalization. Front Psychol. 2020;11:552740. doi:10.3389/fpsyg.2020.552740

7. Qu QF, Wang C. Research of Correlation between typr C personality and maligant Cancer. J Modern Oncol. 2018;26:1458-1462.

8. García-Torres F, Castillo-Mayén R. Differences in eysenck's personalitydimensions between a group of breast cancer survivors and the gene-ral population. Int J Environ Res Public Health. 2019;16 (7):1240. doi:10.3390/ijerph16071240
9. Bonilla LDH, Castellanos FA, Delgado JDT. Psycho-oncological aspects of breast cancer, and impact of integral intervention on the quality of life in patients of cucuta-Colombia. Arch Venez Farmacol Ter. 2020;39(3):373-377.

10. Niu J, Cui J, Yang K, et al. Effect of type C personality behavior pattern on psychological resilience and benefit finding level. Chine Nursing Res. 2020;34:3606-3610.

11. Zhang ZJ. Manual of Behavioral Medicine Scales. 1st ed ed. Beijing: China Medical Electronic Audio and Video Publishing House; 2005: p.160-161.

12. Chen Y, Hao Y, Huang Y, et al. An injectable, near-infrared light-responsive click cross-linked azobenze-ne hydrogel for breast cancer chemotherapy. $J$ Biomed Nanotechnol. 2019;15 (9):1923-1936. doi:10.1166/jbn.2019.2821

13. Sun XY, Ma F, Tian PF, et al. Clinical efficacy of cyclophosphamide metronomic therapy in the treatment of advanced breast cancer and evaluations of adverse reactions. Oncol Progress. 2020;18:924-927.

14. Xu M, Gong SJ. Stepwise multiple regression analysis and survey of self-image of breast cancer patients. Nursing Practice Res. 2020;17:63-65.

15. Özlem B, Ar Y. Does marital adjustment mediate type c personality-depressive symptoms relation? A comparison between breast cancer patients and cancer-free women. Current Psychol. 2019;38(5):1310-1317. doi:10.1007/s12144-017-9693-6

16. Du CF. The relationship between anxiety and depression and Type $\mathrm{C}$ behavior in patients with gynecological malignant tumor during perioperative period. J Int Psychiatry. 2020;47:1219-1221+1225.

17. Zhou CL, Wu YN, Li WJ, et al. Correlation study between personality traits and chemotherapy related symptoms in patients with breast cancer during postoperative Chinese Nursing Research chemotherapy. Chine Nursing Res. 2016;30:1812-1815.

18. Yan H. Effect of Chinese medicine comprehensive therapy on quality of life after breast cancer operation. Nanjing Univ Traditional Chine Med. 2017;2:60-67.

19. Shen XH, Jiang QJ. Report on application of Chinese version of MCMQ in 701 patients. Chine J Behav Med Brain Sci. 2000;54:22-24.

20. Xiao SY. The theoretical basis and research application of social support rating scale. J Clin Psychiatry. 1994;1:98-100.

21. Hon WK, Lam WW, Law CC, Fu YT, Fielding R. Measuring social relational quality in colorectal cancer:the social relational quality scale(SRQS). Psych-Ooncolgy. 2009;18(10):1097-1105. doi: 10.1002 /pon. 1500

22. Zhao HP, Wang J. Social support and hope for hemodialysis patients. Chinese J Nursing. 2000;3:49-51.

23. Wei M, Guo L, Zhu YR, et al. Type C personality and depression among newly diagnosed breast cancer patients:the mediating role of sense of coherence. Neuropsych Dis Treat. 2019;15:3519-3529. doi:10.2147/NDT.S230278

24. Zhou HL, Li M, Wang J. Correlation between perioperative negative emotion and type $\mathrm{C}$ behavior in patients undergoing radical operation for cervical cancer. Chinese $J$ Clin Oncol Rehabilitation. 2018;25:542-545.

25. Su D, Wu XN, Li HP, et al. The correlation study between the serum cortisol and $\mathrm{C}$ type behaviors of perioperative patients with lung cancer. Chine J Practical Nursing. 2015;31:1531-1533.

26. Janowski K, Tatala M, Jedynak T, et al. Social support and psychosocial functioning in women after mastectomy. Palliat Support Care. 2020;18(3):314-321. doi:10.1017/S1478951519000774

27. Todorov N, Sherman KA, Kilby CJ. Self-compassion and hope in the context of body image disturbance and distress in breast cancer survivors. Psycho-Oncology. 2019;28(10):2025-2032. doi:10.1002/ pon.5187

28. Wang WL, Zhou YQ, Chai NN, et al. Mediation and mode ration analyses: exploring the complex pathways between hope and quality of life among patients with schizophrenia. BMC Psychiatry. 2020;20 (1):22. doi:10.1186/s12888-020-2436-5 
29. Dorsett P, Geraghty T, Sinnott A, et al. Hope, coping and psychosocial adjustment after spinal cord injury. Spinal Cord Ser Cases. 2017;3:17046. doi: $10.1038 /$ scsandc

30. Zhu HJ, Guan XH. Impact of spouse synchronous cognitive therapyand psychological intervention on patients with breast diseases surgery mood and behavior characteristic. Chine General Pract. 2016;19:332-334.
31. JiangQJ. Medical Psychology - Theory, Method and Clinical Practice. 1st ed ed. Beijing: People's Medical Publishing House; 2012:p.140-141.

\section{Publish your work in this journal}

Psychology Research and Behavior Management is an international, peer-reviewed, open access journal focusing on the science of psychology and its application in behavior management to develop improved outcomes in the clinical, educational, sports and business arenas. Specific topics covered in the journal include: Neuroscience, memory and decision making; Behavior modification and management; Clinical applications; Business and sports performance management; Social and developmental studies; Animal studies. The manuscript management system is completely online and includes a very quick and fair peer-review system, which is all easy to use. Visit http://www. dovepress.com/testimonials.php to read real quotes from published authors. 